Article

\title{
Trimester-Specific Dietary Intakes in a Sample of French-Canadian Pregnant Women in Comparison with National Nutritional Guidelines
}

\author{
Claudia Savard 1,2,3, Simone Lemieux 1,3, S. John Weisnagel 2,4 , Bénédicte Fontaine-Bisson ${ }^{5,6}$, \\ Claudia Gagnon 2,3,4, Julie Robitaille 1,2,3 and Anne-Sophie Morisset 1,2,3,*
}

1 School of Nutrition, Laval University, Québec City, QC G1V 0A6, Canada; claudia.savard.4@ulaval.ca (C.S.); simone.lemieux@fsaa.ulaval.ca (S.L.); julie.robitaille@fsaa.ulaval.ca (J.R.)

2 Endocrinology and Nephrology Unit, CHU de Québec-Université Laval Research Center, Québec City, QC G1V 4G2, Canada; john.weisnagel@crchudequebec.ulaval.ca (S.J.W.);

claudia.gagnon@crchudequebec.ulaval.ca (C.G.)

3 Institute of Nutrition and Functional Foods, Laval University, Québec City, QC G1V 0A6, Canada

4 Department of Medicine, Laval University, Québec City, QC G1V 0A6, Canada

5 School of Nutrition Sciences, University of Ottawa, Ottawa, ON K1N 6N5, Canada; bfontain@uottawa.ca

6 Institut du Savoir Montfort, Montfort Hospital, Ottawa, ON K1K 0T2, Canada

* Correspondence: anne-sophie.morisset@fsaa.ulaval.ca; Tel.: +1-418-656-2131 (ext. 13982)

Received: 14 May 2018; Accepted: 12 June 2018; Published: 14 June 2018

\begin{abstract}
Diet during pregnancy greatly impacts health outcomes. This study aims to measure changes in dietary intakes throughout trimesters and to assess pregnant women's dietary intakes in comparison with current Canadian nutritional recommendations. Seventy-nine pregnant women were recruited and completed, within each trimester, three Web-based 24-h dietary recalls and one Web questionnaire on supplement use. Dietary intakes from food, with and without supplements, were compared to nutritional recommendations throughout pregnancy. Energy and macronutrient intakes remained stable throughout pregnancy. A majority of women exceeded their energy and protein requirements in the first trimester, and fat intakes as a percentage of energy intakes were above recommendations for more than half of the women in all trimesters. Supplement use increased dietary intakes of most vitamins and minerals, but $20 \%$ of women still had inadequate total vitamin D intakes and most women had excessive folic acid intakes. This study showed that pregnant women did not increase their energy intakes throughout pregnancy as recommended. Furthermore, although prenatal supplementation reduces the risk of inadequate intake for most micronutrients, there is still a risk of excessive folic acid and insufficient vitamin D intake, which needs further investigation.
\end{abstract}

Keywords: pregnancy; dietary intakes; energy intakes; supplements; dietary reference intakes (DRIs)

\section{Introduction}

Pregnancy is a critical period during which the pregnant woman's diet must provide enough nutrients to ensure optimal fetal development as well as to sustain the mother's physiological needs. In fact, in addition to the metabolic demand associated with the fetus' growth, rises in blood volume, extracellular liquids, adipose tissue, and placental weight all lead to an increase in the mother's dietary requirements [1,2]. Consequently, as recommended by the Institute of Medicine and Health Canada, daily pre-pregnancy energy intakes should be increased by 340 and $452 \mathrm{kcal}$ in the second and third trimesters, respectively, in order to create a positive energy balance [3,4]. Likewise, pregnant women should increase their protein intakes in the second and third trimesters, but no specific recommendation exists for carbohydrates and fats during pregnancy [3]. 
Higher energy intakes should allow pregnant women to meet their higher essential fatty acid, dietary fiber, folic acid, iron, vitamin $\mathrm{D}$, calcium, vitamin $\mathrm{B}_{12}$, and vitamin $\mathrm{C}$ requirements $[3,4]$. However, previous research highlighted various dietary inadequacies, namely folate, iron, vitamin $B_{12}$, and vitamin D insufficiencies [5-7] thus suggesting that pregnant women may have difficulty meeting their higher micronutrient requirements through diet alone [5]. Moreover, since inadequate folate and iron status during pregnancy has been associated with numerous adverse health outcomes [8-10], Health Canada recommends that pregnant women should take, on a daily basis, a multivitamin that contains at least $400 \mu \mathrm{g}$ of folic acid and $16-20 \mathrm{mg}$ of iron [4]. There are currently no specific recommendations in terms of supplementation for other micronutrients. The use of a multivitamin combined with the increase in total energy intakes is probably sufficient to allow pregnant women to fill other micronutrient requirements [11].

Dietary intakes should be examined throughout pregnancy in order to detect potential excesses or deficiencies in macro- and micronutrients associated with adverse pregnancy outcomes [12-14]. However, to date, few studies have assessed pregnant women's dietary intakes by considering both food and supplement sources, and even fewer have done so in each trimester of pregnancy [15-20]. To our knowledge, no study assessed trimester-specific adequacy to current nutritional Canadian recommendations. This study aimed to: (1) measure changes in energy and macronutrient intakes across trimesters; and (2) assess pregnant women's dietary intakes in comparison with current Canadian nutritional recommendations.

\section{Materials and Methods}

\subsection{Study Population}

Eighty-six (86) pregnant women recruited from April 2016 to May 2017 at the CHU de QuébecUniversité Laval (Québec City, QC, Canada) were included in the ANGE (Apports Nutritionnels durant la GrossessE) project. Women younger than 18 years old and with a gestational age greater than 11 weeks of pregnancy at the time of recruitment were excluded. Women with a previously diagnosed severe medical condition (i.e., type 1 or type 2 diabetes, renal disease, inflammatory and autoimmune disorders) were also excluded. Our final sample included 79 women for whom we have nutritional data in all trimesters. The ANGE project was approved by the CHU de Québec-Université Laval Research Center's Ethics Committee and participants gave their informed written consent at their first visit to the research center.

\subsection{The Automated Web-Based 24-h Recall (R24W)}

In the first (range: 8.4-14.0 weeks), second (range: 19.3-28.3 weeks), and third (range: 31.9-37.7 weeks) trimesters of pregnancy, each participant was asked to complete a total of three Web-based 24-h dietary recalls, using the R24W (Rappel de $24 \mathrm{~h}$ Web; $24 \mathrm{~h}$ dietary recall) platform, on two weekdays and one weekend day (total of nine dietary recalls throughout pregnancy). The development of the R24W has been previously described [21]. Briefly, the R24W uses a sequence of questions inspired by the United States Department of Agriculture (USDA) Automated Multiple Pass Method (AMPM) [22]. The application sends automatic emails on randomly chosen dates to remind the participants to complete the recall. Participants were required to watch a mandatory tutorial video prior to their first recall. The database includes 2865 food items that are linked to the Canadian Nutrient File [23] to enable automatic extraction of nutrient values. Participants can report an unlimited number of meals and snacks for a 24-h period. Pictures depicting multiple portion sizes with corresponding units and/or volume are available for more than $80 \%$ of all food items. After selecting a food item, participants must choose the picture that best represents the amount of food eaten. In addition, systematic questions are asked about frequently forgotten food items including toppings, condiments, fats, snacks, and drinks. The R24W was previously validated in pregnant women for each trimester [24]. All food items were automatically coded using the 2015 version of the Canadian Nutrient File [23] and data for energy and 22 nutrients were analyzed. 


\subsection{Supplement Use}

Information regarding dietary and prenatal supplement use was obtained through a Web questionnaire administered within each trimester. Participants had to identify their supplement (e.g., brand name, type of supplement, specific nutrient, etc.), and provide its drug identification number (DIN), its measurement unit (e.g., tablets, drops, grams, milliliters, etc.), the dosage, and the frequency at which the reported dose was taken. Participants could enter as many as 10 dietary supplements. The Health Canada Licensed Natural Health Product Database [25] as well as companies' product labels and websites were used to collect the nutritional information of all supplements entered by participants. If information was missing or was incomplete for any of the supplements' characteristics, a research assistant contacted the participant to obtain the missing information. We assessed supplement use by compiling types of supplements used (multivitamins or single-nutrient supplements) and the number of users for each type of supplement.

\subsection{Estimated Energy and Protein Requirements}

Pre-pregnancy body weight was self-reported and height was measured at baseline to calculate pre-pregnancy BMI. Participants completed the validated French version of the Pregnancy Physical Activity Questionnaire (PPAQ) [26,27] within each trimester. Physical activity levels (PALs) were determined by ranking the participants according to the total amount of time they engaged in moderate and high-intensity activities (minutes/day). According to the Institute of Medicine (IOM) guidelines for the general adult population (which includes pregnant women) [3], participants were either considered sedentary (less than $30 \mathrm{~min}$ of moderate-intensity activity), low-active (30 to $60 \mathrm{~min}$ of moderate-intensity activity), active (60 to $180 \mathrm{~min}$ of moderate-intensity activity or 30 to $60 \mathrm{~min}$ of high-intensity activity) or very active (more than $180 \mathrm{~min}$ of moderate-intensity activity or more than $60 \mathrm{~min}$ of high-intensity activity). Estimated energy requirements (EERs) were calculated for each trimester by using pre-pregnancy weight, age, height, and physical activity coefficient corresponding to the PAL determined by the PPAQ [3]. An additional $340 \mathrm{kcal}$ and $452 \mathrm{kcal}$ were respectively added to the second and third trimester EERs [3]. Daily protein requirements were calculated as $1.1 \mathrm{~g} / \mathrm{kg}$ of pre-pregnancy weight for the first 20 weeks of pregnancy, to which $25 \mathrm{~g}$ of protein per day was added for the remaining 20 weeks of pregnancy [3].

\subsection{Other Variables}

Gestational age (weeks of gestation) was confirmed by ultrasound conducted at the CHU de Québec-Université Laval in the first trimester. A Web-based self-administered questionnaire was completed by all participants either in the first $(n=62)$ or in the second $(n=24)$ trimester to collect information on economic and socio-demographic characteristics.

\subsection{Statistical Analyses}

within each trimester, means and standard deviations for energy and macro- and micronutrient intakes as well as the percentage of energy from carbohydrates (\% carbohydrates), fat ( $\%$ fat), and proteins (\% proteins) were calculated from the three $24-\mathrm{h}$ dietary recalls. Total micronutrient intakes were calculated by combining intakes from supplements and intakes from food sources only (derived from the dietary recalls). We then compared total energy and nutrient intakes and intakes from food sources only with dietary reference intakes (DRIs) by calculating proportions of women that had intakes below the estimated average intakes (EARs) and above the upper intake limit (UL), as applicable [28]. Folate intakes as dietary folate equivalent (DFE) were compared to the EAR $(520 \mu \mathrm{g})$, and only synthetic forms of folic acid (i.e., fortified foods and supplements) were compared to the UL for folic acid $(1000 \mu \mathrm{g})$, as the UL for folic acid applies only to synthetic forms [3]. Similarly, only niacin and magnesium intakes from supplements were compared to the UL for these nutrients, as their respective UL only applies to intakes from supplements [3]. Energy intakes (EIs) were compared 
with EERs, and protein, carbohydrate, and fat intakes as percentages of energy were compared with the acceptable macronutrient distribution range (AMDR) [3]. Proportions of women with values below or above the EERs or AMDR were calculated. Protein intakes (g/day) were also compared to estimated protein requirements, as previously described [3]. Finally, repeated measures ANOVA was performed to assess variations in energy, macro- and micronutrient intakes across trimesters. All statistical analyses were performed in JMP version 13 (SAS Institute Inc., Cary, NC, USA).

\section{Results}

Participant characteristics are presented in Table 1. Of the 86 pregnant women recruited, seven were lost to follow-up, mainly due to miscarriage or lack of time to devote to the project. Therefore, results include 79 pregnant women with a mean age of $32.1 \pm 3.7$ years and an average pre-pregnancy BMI of $25.7 \pm 5.8 \mathrm{~kg} / \mathrm{m}^{2}$. The majority of participants were Caucasian (97.5\%), had a university degree $(78.5 \%)$, an annual household income of $C \$ 80,000$ or more $(63.3 \%)$, and were multiparous $(64.6 \%)$.

Table 1. Participants' characteristics $(n=79)$.

\begin{tabular}{|c|c|}
\hline Variables & Mean $\pm \mathrm{SD}$ or $N(\%)$ \\
\hline Age (years) & $32.1 \pm 3.7$ \\
\hline Weeks of gestation at baseline (weeks) & $9.3 \pm 0.7$ \\
\hline Primiparous & $28(35.4)$ \\
\hline BMI $\left(\mathrm{kg} / \mathrm{m}^{2}\right)$ & $25.7 \pm 5.8$ \\
\hline Underweight & $2(2.5)$ \\
\hline Normal weight & $43(54.4)$ \\
\hline Overweight & $19(24.1)$ \\
\hline Obese & $15(19.0)$ \\
\hline Ethnicity-Caucasian & $77(97.5)$ \\
\hline \multicolumn{2}{|l|}{ Education } \\
\hline High school & $4(5.0)$ \\
\hline College & $13(16.5)$ \\
\hline University & $62(78.5)$ \\
\hline \multicolumn{2}{|l|}{ Household income } \\
\hline$<\mathrm{C} \$ 40,000$ & $5(6.3)$ \\
\hline $\mathrm{C} \$ 40,000-59,999$ & $10(12.7)$ \\
\hline $\mathrm{C} \$ 60,000-79,999$ & $13(16.5)$ \\
\hline $\mathrm{C} \$ 80,000-99,999$ & $17(21.5)$ \\
\hline$>\mathrm{C} \$ 100,000$ & $33(41.8)$ \\
\hline Income missing & $1(1.2)$ \\
\hline \multicolumn{2}{|c|}{ Physical activity level (minutes of moderate and vigorous activity/day) } \\
\hline First trimester & $60.5 \pm 59.6$ \\
\hline Second trimester & $45.9 \pm 51.1$ \\
\hline Third trimester & $35.2 \pm 41.5$ \\
\hline
\end{tabular}

\subsection{Supplement Use}

Prenatal multivitamins were used by a majority of pregnant women $(86.1 \%, 84.8 \%$, and $78.5 \%$ in the first, second, and third trimesters, respectively) and folic acid supplements were the most commonly reported single-nutrient supplements (data not shown). Among women that did not take a multivitamin, the most reported single nutrient taken was folic acid for all trimesters (data not shown). Furthermore, among participants taking two supplements, the most reported single nutrients combined with a multivitamin were folic acid (50.0\%) vitamin D (40.0\%), and iron $(44.4 \%)$ in the first, second, and third trimesters, respectively (data not shown). Small proportions $(<10 \%)$ of women reported taking vitamin $\mathrm{D}$, iron, and omega-3 as single-nutrient supplements throughout pregnancy (data not shown). In the third trimester, women who reported taking no supplement were significantly younger 
than the women who were taking at least one supplement $(30.3 \pm 3.8$ years old vs. $32.6 \pm 3.5$ years old, $p=0.0236$; data not shown).

\subsection{Energy, Macronutrients, and Dietary Fiber}

Table 2 shows trimester-specific energy intakes and macronutrient intakes as percentages of energy intake derived from the dietary recalls in comparison with EERs and AMDRs. No significant difference was observed for energy, protein, carbohydrate, or lipid intakes across trimesters. However, a significant increase in SFAs and a decrease in PUFAs as percentages of energy intakes were observed across trimesters (Table 2). Macronutrient intakes (grams per day) derived from the R24Ws and proportions of women that reported intakes above or below the corresponding DRIs are shown in Table 3. Mean energy intakes exceeded EERs in the first trimester (2294.3 \pm 487.2 vs. $2122.4 \pm 265.9 \mathrm{kcal} ; p=0.006)$, but were below EERs in the third trimester $(2234.6 \pm 476.1 \mathrm{vs}$. $2492.2 \pm 216.8 \mathrm{kcal} ; p<0.0001)$. Protein intakes as a percentage of energy were within the acceptable distribution range (10-35\%) in all trimesters but exceeded estimated requirements $(1.1 \mathrm{~g} / \mathrm{kg})$ in the first trimester $(96.7 \pm 20.7$ vs. $70.0 \pm 8.6 \mathrm{~g} /$ day; $p<0.0001)$ for almost all participants $(94.9 \%$ of them). In all trimesters, a majority of women reported fat intakes that were above the acceptable distribution range as a percentage of energy intakes. Inversely, carbohydrate intakes as percentages of energy were below the acceptable distribution range for more than $20 \%$ of participants for each trimester. Dietary fiber intakes were also below the DRI of $14 \mathrm{~g} / 1000 \mathrm{kcal}$ in all trimesters for more than 85\% of participants.

\subsection{Vitamins and Minerals}

Micronutrient intakes derived from the R24Ws (food sources only) and proportions of women that reported intakes above or below the corresponding DRIs are shown in Table 4. A high prevalence of inadequate intakes was observed for vitamin D $(93.7 \%, 83.5 \%, 78.5 \%)$, iron $(88.6 \%, 89.9 \%, 94.9 \%)$, and folate $(58.2 \%, 60.8 \%, 68.4 \%)$ in all trimesters, when only food sources were considered (Table 4 ). Vitamin $\mathrm{B}_{6}$ intakes were below the EAR for $36.7 \%, 32.9 \%$, and $38.0 \%$ of women in the first, second, and third trimesters, respectively. Smaller proportions of women reported, throughout pregnancy, inadequate intakes of magnesium, vitamin A, calcium, and zinc. Vitamin C intakes were inadequate for $22.8 \%$ of participants in the second trimester but only for $4.1 \%$ and $10.1 \%$ of women in the first and third trimesters, respectively. Repeated measures ANOVA showed significant decreases in dietary intakes of vitamin $C$ and manganese, as well as significant increases in dietary calcium and vitamin $B_{12}$ intakes across trimesters (Table 4). In all trimesters, a majority of pregnant women reported sodium intakes that were above the UL of $2300 \mathrm{mg}$.

As shown in Table 5, when food sources and dietary supplements were combined, the proportion of women with adequate micronutrient intakes increased. With the exception of folate, vitamin D, and iron, less than $15 \%$ of our participants had total micronutrient intakes below the EAR, in all trimesters. Total intakes of folic acid and sodium were above the UL for a majority of women, and more than a third of participants had total iron intakes above the UL for all trimesters. The significant decrease observed for vitamin $C$ and manganese, as well as the significant increase in calcium intakes persisted after the addition of intakes from supplements (Table 5). 
Table 2. Trimester-specific energy intakes and macronutrient intakes as percentage of energy intakes in comparison with dietary reference intakes.

\begin{tabular}{|c|c|c|c|c|c|c|c|c|c|c|}
\hline & & First Trimester & & & Second Trimester & & & Third Trimester & & \\
\hline & $\begin{array}{l}\text { Mean } \pm \text { SD or } \\
\text { AMDR Range }\end{array}$ & $\begin{array}{c}\text { \%Below AMDR } \\
\text { or EER }\end{array}$ & $\begin{array}{l}\text { \%Above AMDR } \\
\text { or EER }\end{array}$ & $\begin{array}{l}\text { Mean } \pm \text { SD or } \\
\text { AMDR Range }\end{array}$ & $\begin{array}{c}\text { \%Below AMDR } \\
\text { or EER }\end{array}$ & $\begin{array}{l}\text { \%Above AMDR } \\
\text { or EER }\end{array}$ & $\begin{array}{l}\text { Mean } \pm \text { SD or } \\
\text { AMDR Range }\end{array}$ & $\begin{array}{l}\text { \%Below AMDR } \\
\text { or EER }\end{array}$ & $\begin{array}{l}\text { \%Above AMDR } \\
\text { or EER }\end{array}$ & $p$-Value ${ }^{\text {a }}$ \\
\hline EER (kcal/day) & $2122.4 \pm 265.9$ & - & - & $2403.4 \pm 241.1$ & & - & $2492.2 \pm 216.8$ & - & - & \\
\hline Energy intake (kcal/day) & $2294.3 \pm 487.2$ & 36.7 & 63.3 & $2320.2 \pm 519.1$ & 60.8 & 39.2 & $2234.6 \pm 476.1$ & 70.9 & 29.1 & 0.09 \\
\hline AMDR protein, E\% & $10-35$ & - & - & $10-35$ & - & - & $10-35$ & - & - & - \\
\hline Protein, E\% & $16.9 \pm 2.5$ & 0 & 0 & $17.3 \pm 2.9$ & 0 & 0 & $17.9 \pm 3.3$ & 0 & 0 & 0.14 \\
\hline AMDR carbohydrate, E\% & $45-65$ & - & - & $45-65$ & & & $45-65$ & - & - & \\
\hline Carbohydrate, E\% & $49.4 \pm 4.7$ & 20.3 & 0 & $48.3 \pm 5.7$ & 24.1 & 0 & $48.3 \pm 5.5$ & 24.1 & 0 & 0.27 \\
\hline AMDR total fat, E\% & 20-35 & - & - & $20-35$ & - & - & 20-35 & - & - & - \\
\hline Total fat, $\mathrm{E} \%$ & $35.1 \pm 4.0$ & 0 & 50.6 & $35.8 \pm 4.9$ & 0 & 55.7 & $35.5 \pm 4.4$ & 0 & 57.0 & 0.53 \\
\hline SFA, E\% & $12.8 \pm 2.1$ & - & - & $13.2 \pm 2.9$ & - & - & $13.5 \pm 2.5$ & - & - & 0.047 \\
\hline MUFA, E\% & $12.3 \pm 2.1$ & - & - & $12.6 \pm 2.0$ & - & - & $12.5 \pm 2.1$ & - & - & 0.49 \\
\hline PUFA, E\% & $7.1 \pm 1.9$ & - & - & $7.1 \pm 2.0$ & - & - & $6.5 \pm 1.8$ & - & - & 0.03 \\
\hline
\end{tabular}

Table 3. Trimester-specific macronutrient intakes in comparison with dietary reference intakes.

\begin{tabular}{|c|c|c|c|c|c|c|c|c|c|c|}
\hline & \multicolumn{3}{|c|}{ First Trimester } & \multicolumn{3}{|c|}{ Second Trimester } & \multicolumn{3}{|c|}{ Third Trimester } & \multirow[b]{2}{*}{$p$-Value ${ }^{\text {a }}$} \\
\hline & Mean \pm SD & $\begin{array}{l}\text { \%Below EPR } \\
\text { or AI }\end{array}$ & $\begin{array}{c}\text { \%Above EPR } \\
\text { or AI }\end{array}$ & Mean \pm SD & $\begin{array}{c}\text { \%Below EPR } \\
\text { or AI } \\
\end{array}$ & $\begin{array}{c}\text { \%Above EPR } \\
\text { or AI }\end{array}$ & Mean \pm SD & $\begin{array}{l}\text { \%Below EPR } \\
\text { or AI }\end{array}$ & $\begin{array}{c}\text { \%Above EPR } \\
\text { or AI }\end{array}$ & \\
\hline EPR, g/day & $70.0 \pm 8.6$ & - & - & $95.0 \pm 8.6$ & - & - & $95.0 \pm 8.6$ & - & - & - \\
\hline Protein, g/day & $96.7 \pm 20.7$ & 5.1 & 94.9 & $99.1 \pm 20.9$ & 48.1 & 51.9 & $98.2 \pm 22.0$ & 43.0 & 57.0 & 0.64 \\
\hline Carbohydrate, g/day & $283.3 \pm 68.8$ & - & - & $280.3 \pm 70.9$ & - & - & $270.1 \pm 68.0$ & - & - & 0.14 \\
\hline Total fat, $\mathrm{g} /$ day & $89.6 \pm 21.7$ & - & - & $93.1 \pm 27.5$ & - & - & $88.6 \pm 23.6$ & - & - & 0.20 \\
\hline Dietary fiber, g/day & $23.3 \pm 7.0$ & 96.2 & 3.8 & $23.9 \pm 8.0$ & 87.3 & 12.7 & $22.9 \pm 6.7$ & 89.9 & 10.1 & 0.50 \\
\hline$\omega-6$ Linoleic acid, g/day & $14.8 \pm 5.4$ & - & - & $14.5 \pm 5.3$ & - & - & $13.4 \pm 5.3$ & - & - & 0.07 \\
\hline$\omega-3$ Linolenic acid, g/day & $2.0 \pm 0.7$ & - & - & $2.0 \pm 0.9$ & - & - & $1.9 \pm 0.9$ & - & - & 0.38 \\
\hline Cholesterol, mg/day & $297.2 \pm 99.7$ & - & - & $291.1 \pm 91.7$ & - & - & $288.1 \pm 109.0$ & - & - & 0.81 \\
\hline
\end{tabular}

is used instead of a 0 . EPR: estimated protein requirement $(1.1 \mathrm{~g} / \mathrm{kg}$ or pre-pregnancy weight for the first half of pregnancy and $1.1 \mathrm{~g} / \mathrm{kg}$ of pre-pregnancy weight $+25 \mathrm{~g}$ for the second half). AI: adequate intake. 
Table 4. Trimester-specific micronutrient intakes from food alone in comparison with dietary reference intakes.

\begin{tabular}{|c|c|c|c|c|c|c|c|c|c|c|c|c|}
\hline & \multirow{2}{*}{ EAR } & \multirow{2}{*}{ UL } & \multicolumn{3}{|c|}{ First Trimester } & \multicolumn{3}{|c|}{ Second Trimester } & \multicolumn{3}{|c|}{ Third Trimester } & \multirow[b]{2}{*}{$p$-Value ${ }^{\mathrm{a}}$} \\
\hline & & & Mean \pm SD & \%Below EAR & \%Above UL & Mean \pm SD & \%Below EAR & \%Above UL & Mean \pm SD & \%Below EAR & \%Above UL & \\
\hline Vitamin D, IU/day & 400 & 4000 & $234.8 \pm 119.0$ & 93.7 & 0 & $261.2 \pm 135.2$ & 83.5 & 0 & $271.9 \pm 150.2$ & 78.5 & 0 & 0.11 \\
\hline Iron, mg/day & 22 & 45 & $15.3 \pm 4.8$ & 88.6 & 0 & $15.8 \pm 5.2$ & 89.9 & 0 & $14.8 \pm 4.2$ & 94.9 & 0 & 0.09 \\
\hline Folate, $\mu \mathrm{g}$ DFE/day & 520 & - & $516.2 \pm 139.5$ & 58.2 & - & $495.4 \pm 143.3$ & 60.8 & - & $490.1 \pm 141.3$ & 68.4 & - & 0.31 \\
\hline Folic acid, $\mu \mathrm{g} /$ day & - & 1000 & $155.0 \pm 65.5$ & - & 0 & $146.8 \pm 72.6$ & - & 0 & $138.3 \pm 72.1$ & - & 0 & 0.17 \\
\hline Vitamin $B_{6}, \mathrm{mg} /$ day & 1.6 & 100 & $1.8 \pm 0.5$ & 36.7 & 0 & $1.9 \pm 0.5$ & 32.9 & 0 & $1.8 \pm 0.5$ & 38.0 & 0 & 0.32 \\
\hline Magnesium, mg/day & $290-300$ & 350 & $381.2 \pm 103.8$ & 17.8 & - & $391.9 \pm 108.9$ & 19.0 & - & $386.2 \pm 106.4$ & 20.3 & - & 0.65 \\
\hline Vitamin A, $\mu \mathrm{g}$ RAE/day & 550 & 3000 & $879.2 \pm 305.9$ & 13.9 & 0 & $906.4 \pm 392.5$ & 17.7 & 0 & $916.2 \pm 398.4$ & 17.7 & 0 & 0.71 \\
\hline Zinc, mg/day & 9,5 & 40 & $12.5 \pm 3.2$ & 12.7 & 0 & $13.4 \pm 3.2$ & 8.9 & 0 & $13.2 \pm 3.7$ & 11.4 & 0 & 0.15 \\
\hline Calcium, mg/day & 800 & 2500 & $1292.3 \pm 381.8$ & 10.1 & 0 & $1350.3 \pm 515.9$ & 13.9 & 2.5 & $1427.0 \pm 506.0$ & 6.3 & 1.3 & 0.02 \\
\hline Vitamin $C, \mathrm{mg} /$ day & 70 & 2000 & $159.5 \pm 66.7$ & 5.1 & 0 & $137.9 \pm 81.4$ & 22.8 & 0 & $138.4 \pm 66.6$ & 10.1 & 0 & 0.01 \\
\hline Thiamin, $\mathrm{mg} /$ day & 1.2 & - & $1.9 \pm 0.6$ & 5.1 & - & $1.9 \pm 0.7$ & 7.6 & - & $1.8 \pm 0.8$ & 7.6 & - & 0.40 \\
\hline Vitamin $B_{12}, \mu \mathrm{g} /$ day & 2.2 & - & $4.8 \pm 1.6$ & 2.5 & - & $5.4 \pm 2.4$ & 3.8 & - & $5.6 \pm 2.5$ & 0 & - & 0.02 \\
\hline Riboflavin, mg/day & 1.2 & - & $2.3 \pm 0.6$ & 1.3 & - & $2.4 \pm 0.6$ & 1.3 & - & $2.5 \pm 0.8$ & 0 & - & 0.07 \\
\hline Niacin, mg NE/day & 14 & 35 & $45.7 \pm 10.6$ & 0 & - & $45.9 \pm 9.2$ & 0 & - & $45.0 \pm 10.3$ & 0 & - & 0.64 \\
\hline Pantothenic acid, mg/day & & & $6.5 \pm 1.8$ & - & - & $6.5 \pm 1.5$ & & & $6.5 \pm 1.6$ & & - & 0.98 \\
\hline Phosphorus, mg/day & 580 & 3500 & $1616.4 \pm 383.7$ & 0 & 0 & $1660.3 \pm 398.0$ & 0 & 0 & $1673.7 \pm 442.1$ & 0 & 0 & 0.47 \\
\hline Sodium, mg/day & - & 2300 & $3406.0 \pm 889.8$ & - & 94.9 & $3276.0 \pm 950.3$ & - & 86.1 & $3199.0 \pm 921.7$ & - & 84.8 & 0.17 \\
\hline Manganese, $\mathrm{mg} /$ day & - & 11 & $4.0 \pm 1.5$ & 0 & 1.3 & $4.3 \pm 1.4$ & - & 0 & $3.9 \pm 1.3$ & - & 0 & 0.005 \\
\hline Selenium, $\mu \mathrm{g} /$ day & 49 & 400 & $135.7 \pm 34.0$ & 0 & 0 & $135.2 \pm 32.1$ & 0 & 0 & $131.8 \pm 30.9$ & 0 & 0 & 0.48 \\
\hline Copper, mg/day & 0.8 & 10 & $1.5 \pm 0.6$ & 1.3 & 0 & $1.6 \pm 0.6$ & 1.3 & 0 & $1.5 \pm 0.5$ & 3.8 & 0 & 0.22 \\
\hline
\end{tabular}

a $p$-value for repeated measures ANOVA performed to assess variations in micronutrient intakes across trimesters. When no EAR or UL was established for a nut
instead of a 0 . EAR: estimated average requirement; UL: upper intake limit; DFE: dietary folate equivalent; RAE: retinol activity equivalents; NE: niacin equivalent. 
Table 5. Trimester-specific total micronutrient intakes (including food sources and supplements) in comparison with dietary reference intakes.

\begin{tabular}{|c|c|c|c|c|c|c|c|c|c|c|c|c|}
\hline & \multirow{2}{*}{ EAR } & \multirow{2}{*}{ UL } & \multicolumn{3}{|c|}{ First Trimester } & \multicolumn{3}{|c|}{ Second Trimester } & \multicolumn{3}{|c|}{ Third Trimester } & \multirow{2}{*}{$p$-Value } \\
\hline & & & Mean \pm SD & \%Below EAR & \%Above UL & Mean \pm SD & \%Below EAR & \%Above UL & Mean \pm SD & \%Below EAR & \%Above UL & \\
\hline Vitamin D, IU/day & 400 & 4000 & $632.2 \pm 555.9$ & 25.3 & 1.3 & $690.0 \pm 538.4$ & 21.5 & 1.3 & $689.4 \pm 544.9$ & 21.5 & 1.3 & 0.15 \\
\hline Iron, mg/day & 22 & 45 & $38.2 \pm 14.0$ & 19.0 & 35.4 & $38.8 \pm 13.8$ & 19.0 & 38.0 & $41.0 \pm 24.7$ & 22.8 & 36.7 & 0.65 \\
\hline Folate, $\mu \mathrm{g}$ DFE/day & 520 & - & $1777.0 \pm 1221.4$ & 7.6 & - & $1763.2 \pm 1313.0$ & 10.1 & - & $1617.6 \pm 1212.2$ & 16.5 & & 0.29 \\
\hline Folic acid, $\mu \mathrm{g} /$ day & - & 1000 & $1415.8 \pm 1213.7$ & & 86.1 & $1412.6 \pm 1313.4$ & & 83.5 & $1265.8 \pm 1199.3$ & & 79.7 & 0.27 \\
\hline Vitamin $B_{6}, \mathrm{mg} /$ day & 1.6 & 100 & $5.6 \pm 3.9$ & 8.9 & 0 & $5.8 \pm 4.0$ & 7.6 & 0 & $5.4 \pm 4.0$ & 8.9 & 0 & 0.29 \\
\hline Magnesium, mg/day & $290-300$ & 350 & $419.1 \pm 108.4$ & 8.9 & 0 & $431.9 \pm 113.9$ & 8.9 & 0 & $424.2 \pm 110.8$ & 11.4 & 0 & 0.62 \\
\hline Vitamin A, $\mu \mathrm{g}$ RAE/day & 550 & 3000 & $1398.1 \pm 574.4$ & 7.6 & 0 & $1415.9 \pm 674.8$ & 7.6 & 0 & $1429.8 \pm 635.5$ & 7.6 & 0 & 0.91 \\
\hline Zinc, mg/day & 9,5 & 40 & $20.4 \pm 6.7$ & 5.1 & 0 & $21.4 \pm 6.6$ & 2.5 & 0 & $21.0 \pm 7.2$ & 3.8 & 0 & 0.36 \\
\hline Calcium, mg/day & 800 & 2500 & $1503.4 \pm 370.6$ & 2.5 & 0 & $1560.0 \pm 551.4$ & 6.3 & 5.1 & $1630.7 \pm 524.4$ & 2.5 & 6.3 & 0.04 \\
\hline Vitamin C, mg/day & 70 & 2000 & $234.7 \pm 79.1$ & 1.3 & 0 & $215.7 \pm 93.3$ & 7.6 & 0 & $213.2 \pm 71.0$ & 2.5 & 0 & 0.04 \\
\hline Thiamin, $\mathrm{mg} /$ day & 1.2 & - & $3.4 \pm 1.3$ & 2.5 & - & $3.5 \pm 1.3$ & 2.5 & - & $3.3 \pm 1.4$ & 2.5 & - & 0.31 \\
\hline Vitamin $B_{12}, \mu \mathrm{g} /$ day & 2.2 & - & $11.0 \pm 8.0$ & 1.3 & - & $10.6 \pm 5.7$ & 0 & - & $10.1 \pm 5.3$ & 0 & - & 0.54 \\
\hline Riboflavin, mg/day & 1.2 & - & $4.0 \pm 1.4$ & 1.3 & - & $4.1 \pm 1.5$ & 0 & - & $4.1 \pm 1.5$ & 0 & - & 0.80 \\
\hline Niacin, mg NE/day & 14 & 35 & $60.1 \pm 13.4$ & 0 & - & $60.8 \pm 12.8$ & 0 & - & $59.3 \pm 14.6$ & 0 & - & 0.64 \\
\hline Pantothenic acid, mg/day & - & - & $11.1 \pm 3.2$ & - & - & $11.1 \pm 3.1$ & - & - & $10.9 \pm 3.1$ & - & - & 0.86 \\
\hline Phosphorus, mg/day & 580 & 3500 & $1618.0 \pm 383.6$ & 0 & 0 & $1665.7 \pm 401.2$ & 0 & 0 & $1673.7 \pm 442.1$ & 0 & 0 & 0.49 \\
\hline Sodium, mg/day & - & 2300 & $3406.0 \pm 889.8$ & 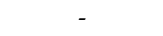 & 94.9 & $3276.0 \pm 950.3$ & - & 86.1 & $3199.0 \pm 921.7$ & - & 84.8 & 0.17 \\
\hline Manganese, mg/day & - & 11 & $5.0 \pm 1.9$ & - & 1.3 & $5.3 \pm 1.8$ & - & 1.3 & $4.9 \pm 1.6$ & - & 0 & 0.04 \\
\hline Selenium, $\mu \mathrm{g} /$ day & 49 & 400 & $151.2 \pm 38.1$ & 0 & 0 & $151.4 \pm 39.2$ & 0 & 0 & $147.6 \pm 37.5$ & 0 & 0 & 0.57 \\
\hline Copper, mg/day & 0.8 & 10 & $2.6 \pm 0.9$ & 1.3 & 0 & $2.7 \pm 1.0$ & 1.3 & 0 & $2.5 \pm 0.9$ & 2.5 & 0 & 0.23 \\
\hline
\end{tabular}

${ }^{a} p$-value for repeated measures ANOVA performed to assess variations in micronutrient intakes across trimesters. When no EAR or UL was established for a nut
instead of a 0. EAR: estimated average requirement; UL: upper intake limit; DFE: dietary folate equivalent; RAE: retinol activity equivalents; NE: niacin equivalent. 


\section{Discussion}

Our prospective assessment of pregnant women's dietary intakes revealed a stability in energy and macronutrient intakes across trimesters. Most women exceeded their estimated requirements in terms of energy and protein in the first trimester but reported energy intakes below their needs later in pregnancy. We also found that diet alone may not be sufficient to provide adequate intakes for all micronutrients. Besides, when only food sources were considered, insufficient intakes of dietary fiber, vitamin D, folate, and iron were observed for a majority of women. Supplement use considerably improved the adequacy of micronutrient intakes among the pregnant women in our study sample, although excessive intakes were observed for iron, folic acid, and sodium.

Although it is recommended for pregnant women to increase their caloric intake as the pregnancy progresses [3], we found that there was a stability in energy intakes throughout pregnancy. Likewise, Abeysekera et al. [29] and Talai Rad et al. [30] as well as Moran et al. [18] found no significant changes in longitudinal caloric intakes of pregnant women. A prospective study by Vioque et al. conducted among Spanish pregnant women even observed a significant decrease in energy intakes (from the first to the third trimester) measured by a food frequency questionnaire (FFQ) [31]. Moreover, a recent meta-analysis of 18 studies by Jebeile et al. [32] reported little to no change in energy intake during pregnancy, which is in line with the stability we observed across trimesters. In light of their observations, Jebeile et al. [32] questioned the current caloric recommendations during pregnancy, suggesting they may be too high, but this affirmation should be further explored through studies that will focus on energy metabolism during pregnancy.

Although no variation in energy and macronutrient intakes was observed, most women exceeded their EER and EPR in the first trimester, in contrast with the third trimester, where a majority of women reported energy intakes below their EER. Kubota et al. [15] reported partially similar results, as they observed dietary intakes in the third trimester that were $900 \mathrm{kcal}$ below the official Japanese recommendations. Since we do not have pre-pregnancy nutritional data, it is unknown whether the caloric excess observed is related to pregnancy itself or if it was already present before pregnancy. Augustine et al. [33] suggested that the process of «eating for two» associated with pregnancy occurs before the actual metabolic demand affects the mother. According to them, hormone-induced increase in dietary intakes early on in pregnancy could represent an adaptive response to the upcoming metabolic demand [33]. This could partially explain why our sample exceeded their EERs and EPRs as early as in the first trimester. The higher protein intakes observed in the first trimester also suggest that foods rich in protein (e.g., meat, dairy, legumes, etc.) may have contributed to the energy excess observed in early pregnancy, but this should be further investigated. Moreover, the questionnaire used to calculate PAL, the PPAQ, has been known to overestimate PAL in a small cohort of pregnant women [34]; therefore, the EERs calculated calculated within each trimester each trimester may have been overestimated. The use of a more precise method to measure our sample's PAL (e.g., an accelerometer), could have attenuated the gap between EIs and EERs in the third trimester but could have increased it in the first trimester.

In parallel with the energy and protein excess observed in the first trimester, we found that, in all trimesters, more than half of our study sample reported fat intakes as percentages of energy that exceeded the acceptable range of $20-35 \%$. These results are similar to those of Dubois et al. [11] in which a third of the 1533 pregnant women studied had total fat intakes as a percentage of energy above the recommended range. Furthermore, a meta-analysis by Blumfield et al. [19] also found that studies set in Western regions reported mean fat intakes (as percentages of energy intakes) of $35.0 \%$ to $37.1 \%$ among pregnant women, in accordance with our results. Moreover, in our study, $20.3 \%$ to $24.1 \%$ of participants reported carbohydrate intakes as a percentage of energy below the recommendations, which is also similar to other North American studies [19]. However, the literature is still incomplete and unclear on the roles that each macronutrient plays in pregnant women's health [35]. Further research is therefore necessary to assess the impact of inadequate macronutrient intakes on maternal and fetal outcomes. 
The suboptimal dietary intakes of fiber, vitamin D, folic acid, and iron observed in pregnant women from our study seem to be in line with the results of various authors [11,18,36-39]. Our results combined with those of other epidemiological studies thus suggest that food fortification policies and the use of a multivitamin during pregnancy are still necessary to reduce the risk of inadequate intake of micronutrients. In fact, our study showed that the use of dietary supplements greatly improved the adherence to micronutrient recommendations, as approximately $75 \%$ of all participants had total intakes above the EAR for all micronutrients. Dubois et al. [11] as well as Fayyaz et al. [40] reported similar results, especially regarding total iron and folate intakes. The insufficient intakes of dietary fiber observed in our study are in accordance with what Dubois et al. [11] reported, however, the relevance of these results and the impact of inadequate fiber intakes during pregnancy should be further investigated.

Most of our participants were supplement users and prenatal multivitamins were the most prevalent supplement taken by our study sample. It is important to mention that, although Health Canada recommends a prenatal multivitamin that contains $400 \mu \mathrm{g}$ of folic acid and 16-20 mg of iron, close to all prenatal multivitamin supplements taken by our participants contained 1000 to $5000 \mu \mathrm{g}$ of folic acid and 27 to $35 \mathrm{mg}$ of iron (data not shown). Consequently, a majority of participants exceeded the UL for folic acid $(1000 \mu \mathrm{g})$ in all trimesters and more than a third exceeded the UL for iron $(45 \mathrm{mg})$ in the first and second trimesters. Dubois et al. [11] obtained similar results as they found that $90.4 \%$ and $32.4 \%$ of their participants had excessive folic acid and iron intakes, respectively, when dietary supplements were taken into account. Increased iron and folic acid intakes are indicated for women with conditions such as iron-deficiency anemia (iron) or for pregnant women at higher risk of giving birth to children with neural tube defects (folic acid) [41,42]. In our study, we do not have information regarding the number of women that were prescribed an iron supplement to prevent or to treat an iron-deficiency anemia. It is therefore impossible to know if the excessive iron intakes observed among our participants were due to anemia prevention or treatment. Moreover, it is important to mention that other nutrients, namely calcium, might decrease iron absorption, and thus observed total intakes of iron may not reflect the real iron status of our participants [43]. For these reasons, our results should be combined with direct assessment of iron status to evaluate the adequacy of our participant's iron intakes. Furthermore, results from a recent Canadian study suggest that although fortification policies improved the population's dietary intakes of folic acid, supplement users may be at risk of folic acid overconsumption [44]. To date, the implications of high folic acid intakes on pregnancy and prenatal health outcomes are not well understood and should therefore be further investigated $[40,45,46]$.

Along with iron and folate, vitamin D was found to be one of the nutrients for which diet alone was insufficient to provide adequate intakes. The prevalence of inadequate intakes did decrease when dietary supplements were taken into account, but more than $20 \%$ of participants sill had total vitamin D intakes that were below the EAR, in all trimesters. Similar inadequacies were reported by Aghajafari et al. [37], as they found that $44 \%$ of their sample ( $n=537$ pregnant women) reported total vitamin D intakes (diet and supplements) that did not meet the Recommended Dietary Allowance (RDA) of $600 \mathrm{IU}$. Furthermore, despite the fact that more than half of their participants reported adequate daily vitamin D intakes ( $\geq 600 \mathrm{IU}$ ), Aghajafari et al. found that $20 \%$ of them were vitamin D-insufficient, according to the Endocrine Society and Osteoporosis Canada's definition of $75 \mathrm{nmol} / \mathrm{L}$ circulating 25-hydroxyvitamin D. [47,48]. Moreover, Hollis et al. [49] conducted a double-blind randomized clinical trial in 494 pregnant women and found that a vitamin D supplementation of $4000 \mathrm{IU} /$ day was the most effective in achieving vitamin D sufficiency, in comparison with 400 and $2000 \mathrm{IU} /$ day. In our study, prenatal multivitamins taken by pregnant women contained, depending on the brand of the multivitamin, between 250 and $600 \mathrm{IU}$ of vitamin D (data not shown). This may not be adequate, according to Hollis et al. [49], to complement dietary intakes of all pregnant women. Nevertheless, evidence regarding vitamin D supplementation during pregnancy is not currently sufficient to support definite clinical recommendations, and the results of Hollis et al. should be interpreted with caution [50]. It would also be necessary to combine dietary assessment (food and 
supplements) with direct measurement of vitamin D status (i.e., circulating 25(OH)D) and sun exposure in order to accurately evaluate vitamin D adequacy during pregnancy [11,51].

To our knowledge, this is the first study to prospectively assess whether or not pregnant women met current Canadian nutritional recommendations. The use of a validated Web-based $24 \mathrm{~h}$ recall combined with a Web questionnaire on supplement use generated detailed information on dietary and total intakes during pregnancy. However, our study has some limitations, namely regarding the small size and the lack of representativeness of our study sample, since most pregnant women enrolled were Caucasians and of a higher socioeconomic status. The nutritional inadequacies observed among our study sample may therefore be greater among less educated and lower-income pregnant women. Nutritional adequacy of pregnant women of lower socioeconomic status should be further investigated. However, despite our small sample size, our results highlight the need for more prospective, population-based studies regarding pregnant women's dietary intakes, especially among lower income, less educated populations. Finally, our study did not measure circulating $25(\mathrm{OH}) \mathrm{D}$ in addition to iron and folate status, which limited our adequacy assessment of pregnant women's vitamin $\mathrm{D}$, iron, and folate intakes.

\section{Conclusions}

In summary, we observed that, contrary to current recommendations, there was a stability in dietary intakes across trimesters, and thus most women exceeded their energy and protein requirements in the first trimester and had intakes below recommendations in the third trimester. The implications and possible causes of excessive energy and protein intakes in early pregnancy are not well documented and should be further investigated in association with gestational weight gain and other metabolic outcomes. The use of prenatal multivitamins and single nutrient supplements considerably improved iron, folate, and vitamin D adequacy, although excessive folic acid, iron, sodium, and niacin intakes were observed, and vitamin D inadequacies persisted for some pregnant women. Further research is needed to, firstly, evaluate the impact of high doses of folic acid on pregnancy and prenatal outcomes, and, secondly, to identify the dose of supplemental vitamin D necessary to achieve vitamin D sufficiency.

Author Contributions: All authors made substantial contributions to the conception and design of the manuscript, and all critically revised a first draft of the manuscript for important intellectual content. C.S. collected the data under the supervision of A.-S.M. and conducted primary statistical analyses of the data with the help of J.R., S.L., S.J.W., B.F.-B., C.G., and A.-S.M. All authors participated in the secondary analyses and interpretation of data. All authors gave their approval of the manuscript's final version to be published and therefore take public responsibility for the content of the manuscript. Finally, all authors agreed to be accountable for all aspects of the work.

Funding: The ANGE project is funded by the Danone Institute of Canada and by startup founds (Fonds de recherche du Québec-Santé et Fondation du CHU de Québec). All funding allowed the collection, analysis, and interpretation of data, but played no role in the writing of this manuscript.

Acknowledgments: We would like to acknowledge the valuable collaboration of trained dietician and graduate student Anne-Sophie Plante, as well as the research team that developed the R24W in collaboration with SL and JR: Benoît Lamarche, Louise Corneau, Catherine Laramée, and Simon Jacques.

Conflicts of Interest: The authors declare no conflict of interest.

\section{References}

1. Butte, N.F.; King, J.C. Energy requirements during pregnancy and lactation. Public Health Nutr. 2005, 8, 1010-1027. [CrossRef] [PubMed]

2. Fowles, E.R.; Fowles, S.L. Healthy eating during pregnancy: Determinants and supportive strategies. J. Community Health Nurs. 2008, 25, 138-152. [CrossRef] [PubMed]

3. Otten, J.J.; Hellwig, J.P.; Meyers, L.D. (Eds.) Dietary Reference Intakes: The Essential Guide to Nutrient Requirements; Institute of Medicine, National Academies Press: Washington, DC, USA, 2006. 
4. Health Canada. Prenatal Nutrition Guidelines for Health Professionals. Background on Canada's Food Guide; Health Canada: Ottawa, ON, Canada, 2009.

5. Gernand, A.D.; Schulze, K.J.; Stewart, C.P.; West, K.P., Jr.; Christian, P. Micronutrient deficiencies in pregnancy worldwide: Health effects and prevention. Nat. Rev. Endocrinol. 2016, 12, 274-289. [CrossRef] [PubMed]

6. Morisset, A.S.; Weiler, H.A.; Dubois, L.; Ashley-Martin, J.; Shapiro, G.D.; Dodds, L.; Massarelli, I.; Vigneault, M.; Arbuckle, T.E.; Fraser, W.D. Rankings of iron, vitamin D, and calcium intakes in relation to maternal characteristics of pregnant Canadian women. Appl. Physiol. Nutr. Metab. 2016, 41, 749-757. [CrossRef] [PubMed]

7. Scholing, J.M.; Olthof, M.R.; Jonker, F.A.; Vrijkotte, T.G. Association between pre-pregnancy weight status and maternal micronutrient status in early pregnancy. Public Health Nutr. 2018, 1-10. [CrossRef] [PubMed]

8. Breymann, C. Iron Deficiency Anemia in Pregnancy. Semin. Hematol. 2015, 52, 339-347. [CrossRef] [PubMed]

9. Goh, Y.I.; Koren, G. Folic acid in pregnancy and fetal outcomes. J. Obstet. Gynaecol. 2008, 28, 3-13. [CrossRef] [PubMed]

10. Martin, J.C.; Zhou, S.J.; Flynn, A.C.; Malek, L.; Greco, R.; Moran, L. The Assessment of Diet Quality and Its Effects on Health Outcomes Pre-pregnancy and during Pregnancy. Semin. Reprod. Med. 2016, 34, 83-92. [PubMed]

11. Dubois, L.; Diasparra, M.; Bédard, B.; Colapinto, C.K.; Fontaine-Bisson, B.; Morisset, A.S.; Tremblay, R.E.; Fraser, W.D. Adequacy of nutritional intake from food and supplements in a cohort of pregnant women in Quebec, Canada: The 3D Cohort Study (Design, Develop, Discover). Am. J. Clin. Nutr. 2017, 106, 541-548. [CrossRef] [PubMed]

12. Al Wattar, B.H.; Mylrea-Lowndes, B.; Morgan, C.; Moore, A.P.; Thangaratinam, S. Use of dietary assessment tools in randomized trials evaluating diet-based interventions in pregnancy: A systematic review of literature. Curr. Opin. Obstet. Gynecol. 2016, 28, 455-463. [CrossRef] [PubMed]

13. Kipnis, V.; Midthune, D.; Freedman, L.S.; Bingham, S.; Schatzkin, A.; Subar, A.; Carroll, R.J. Empirical evidence of correlated biases in dietary assessment instruments and its implications. Am. J. Epidemiol. 2001, 153, 394-403. [CrossRef] [PubMed]

14. Willet, W.C. Nutritional Epidemiology, 3rd ed.; Oxford University Press: New York, NY, USA, 2013.

15. Kubota, K.; Itoh, H.; Tasaka, M.; Naito, H.; Fukuoka, Y.; Muramatsu Kato, K.; Kohmura, Y.K.; Sugihara, K.; Kanayama, N. Changes of maternal dietary intake, bodyweight and fetal growth throughout pregnancy in pregnant Japanese women. J. Obstet. Gynaecol. Res. 2013, 39, 1383-1390. [CrossRef] [PubMed]

16. Lyu, L.C.; Hsu, Y.N.; Chen, H.F.; Lo, C.C.; Lin, C.L. Comparisons of four dietary assessment methods during pregnancy in Taiwanese women. Taiwan. J. Obstet. Gynecol. 2014, 53, 162-169. [CrossRef] [PubMed]

17. McGowan, C.A.; McAuliffe, F.M. Maternal dietary patterns and associated nutrient intakes during each trimester of pregnancy. Public Health Nutr. 2013, 16, 97-107. [CrossRef] [PubMed]

18. Moran, L.J.; Sui, Z.; Cramp, C.S.; Dodd, J.M. A decrease in diet quality occurs during pregnancy in overweight and obese women which is maintained post-partum. Int. J. Obes. (Lond.) 2013, 37, 704-711. [CrossRef] [PubMed]

19. Blumfield, M.L.; Hure, A.J.; Macdonald-Wicks, L.; Smith, R.; Collins, C.E. Systematic review and meta-analysis of energy and macronutrient intakes during pregnancy in developed countries. Nutr. Rev. 2012, 70, 322-336. [CrossRef] [PubMed]

20. Kopp-Hoolihan, L.E.; van Loan, M.D.; Wong, W.W.; King, J.C. Longitudinal assessment of energy balance in well-nourished, pregnant women. Am. J. Clin. Nutr. 1999, 69, 697-704. [CrossRef] [PubMed]

21. Jacques, S.; Lemieux, S.; Lamarche, B.; Laramée, C.; Corneau, L.; Lapointe, A.; Tessier-Grenier, M.; Robitaille, J. Development of a Web-Based 24-h Dietary Recall for a French-Canadian Population. Nutrients 2016, 8, 724. [CrossRef] [PubMed]

22. Moshfegh, A.J.; Rhodes, D.G.; Baer, D.J.; Murayi, T.; Clemens, J.C.; Rumpler, W.V.; Paul, D.R.; Sebastian, R.S.; Kuczynski, K.J.; Ingwersen, L.A.; et al. The US Department of Agriculture Automated Multiple-Pass Method reduces bias in the collection of energy intakes. Am. J. Clin. Nutr. 2008, 88, 324-332. [CrossRef] [PubMed]

23. Canadian Nutrient File (CNF). Available online: https://food-nutrition.canada.ca/cnf-fce/index-eng.jsp (accessed on 26 March 2018).

24. Savard, C.; Lemieux, S.; Lafrenière, J.; Laramée, C.; Robitaille, J.; Morisset, A.S. Validation of a self-administered web-based 24-hour dietary recall among pregnant women. BMC Pregnancy Childbirth 2018, 18, 112. [CrossRef] [PubMed] 
25. Health Canada. Licensed Natural Health Product Database. Available online: https://health-products. canada.ca/lnhpd-bdpsnh/index-eng.jsp (accessed on 26 March 2018).

26. Chandonnet, N.; Saey, D.; Alméras, N.; Marc, I. French Pregnancy Physical Activity Questionnaire compared with an accelerometer cut point to classify physical activity among pregnant obese women. PLoS ONE 2012, 7, e38818. [CrossRef] [PubMed]

27. Chasan-taber, L.; Schmidt, M.D.; Roberts, D.E.; Hosmer, D.A.V.I.D.; Markenson, G.L.E.N.N.; Freedson, P.S. Development and validation of a Pregnancy Physical Activity Questionnaire. Med. Sci. Sports Exerc. 2004, 36, 1750-1760. [CrossRef] [PubMed]

28. Institute of Medicine (US) Subcommittee on Interpretation and Uses of Dietary Reference Intakes; Institute of Medicine (US) Standing Committee on the Scientific Evaluation of Dietary Reference Intakes. Application of DRIs for Group Diet Assessment. In DRI Dietary Reference Intakes: Applications in Dietary Assessment; National Academies Press: Washington, DC, USA, 2000.

29. Abeysekera, M.V.; Morris, J.A.; Davis, G.K.; O'sullivan, A.J. Alterations in energy homeostasis to favour adipose tissue gain: A longitudinal study in healthy pregnant women. Aust. N. Z. J. Obstet. Gynaecol. 2016, 56, 42-48. [CrossRef] [PubMed]

30. Rad, N.T.; Ritterath, C.; Siegmund, T.; Wascher, C.; Siebert, G.; Henrich, W.; Buhling, K.J. Longitudinal analysis of changes in energy intake and macronutrient composition during pregnancy and 6 weeks post-partum. Arch. Gynecol. Obstet. 2011, 283, 185-190.

31. Vioque, J.; Navarrete-Muñoz, E.M.; Gimenez-Monzó, D.; García-de-la-Hera, M.; Granado, F.; Young, I.S.; Ramón, R.; Ballester, F.; Murcia, M.; Rebagliato, M.; et al. Reproducibility and validity of a food frequency questionnaire among pregnant women in a Mediterranean area. Nutr. J. 2013, 12, 26. [CrossRef] [PubMed]

32. Jebeile, H.; Mijatovic, J.; Louie, J.C.Y.; Prvan, T.; Brand-Miller, J.C. A systematic review and metaanalysis of energy intake and weight gain in pregnancy. Am. J. Obstet. Gynecol. 2016, 214, 465-483. [CrossRef] [PubMed]

33. Augustine, R.A.; Ladyman, S.R.; Grattan, D.R. From feeding one to feeding many: Hormone-induced changes in bodyweight homeostasis during pregnancy. J. Physiol. 2008, 586, 387-397. [CrossRef] [PubMed]

34. Brett, K.E.; Wilson, S.; Ferraro, Z.M.; Adamo, K.B. Self-report Pregnancy Physical Activity Questionnaire overestimates physical activity. Can. J. Public Health 2015, 106, e297-e302. [CrossRef] [PubMed]

35. Tielemans, M.J.; Garcia, A.H.; Peralta Santos, A.; Bramer, W.M.; Luksa, N.; Luvizotto, M.J.; Moreira, E.; Topi, G.; De Jonge, E.A.; Visser, T.L.; Voortman, T. Macronutrient composition and gestational weight gain: A systematic review. Am. J. Clin. Nutr. 2016, 103, 83-99. [CrossRef] [PubMed]

36. Roy, A.; Evers, S.E.; Campbell, M.K. Dietary supplement use and iron, zinc and folate intake in pregnant women in London, Ontario. Chronic Dis. Inj. Can. 2012, 32, 76-83. [PubMed]

37. Aghajafari, F.; Field, C.J.; Kaplan, B.J.; Rabi, D.M.; Maggiore, J.A.; O’Beirne, M.; Hanley, D.A.; Eliasziw, M.; Dewey, D.; Weinberg, A.; et al. The Current Recommended Vitamin D Intake Guideline for Diet and Supplements During Pregnancy Is Not Adequate to Achieve Vitamin D Sufficiency for Most Pregnant Women. PLoS ONE 2016, 11, e0157262. [CrossRef] [PubMed]

38. Kocyłowski, R.; Lewicka, I.; Grzesiak, M.; Gaj, Z.; Sobańska, A.; Poznaniak, J.; von Kaisenberg, C.; Suliburska, J. Assessment of dietary intake and mineral status in pregnant women. Arch. Gynecol. Obstet. 2018, 297, 1433-1440. [CrossRef] [PubMed]

39. Blumfield, M.L.; Hure, A.J.; Macdonald-Wicks, L.; Smith, R.; Collins, C.E. A systematic review and meta-analysis of micronutrient intakes during pregnancy in developed countries. Nutr. Rev. 2013, 71, 118-132. [CrossRef] [PubMed]

40. Fayyaz, F.; Wang, F.; Jacobs, R.L.; O'Connor, D.L.; Bell, R.C.; Field, C.J.; APrON Study Team. Folate, vitamin B12, and vitamin B6 status of a group of high socioeconomic status women in the Alberta Pregnancy Outcomes and Nutrition (APrON) cohort. Appl. Physiol. Nutr. Metab. 2014, 39, 1402-1408. [CrossRef] [PubMed]

41. Wilson, R.D.; Audibert, F.; Brock, J.A.; Carroll, J.; Cartier, L.; Gagnon, A.; Johnson, J.A.; Langlois, S.; Murphy-Kaulbeck, L.; Okun, N.; Pastuck, M. Pre-conception Folic Acid and Multivitamin Supplementation for the Primary and Secondary Prevention of Neural Tube Defects and Other Folic Acid-Sensitive Congenital Anomalies. J. Obstet. Gynaecol. Can. 2015, 37, 534-552. [CrossRef]

42. Peña-Rosas, J.P.; De-Regil, L.M.; Dowswell, T.; Viteri, F.E. Daily oral iron supplementation during pregnancy. Cochrane Database Syst. Rev. 2015, CD004736. [CrossRef] [PubMed] 
43. Hallberg, L.; Rossander-Hulten, L.; Brune, M.; Gleerup, A. Calcium and iron absorption: Mechanism of action and nutritional importance. Eur. J. Clin. Nutr. 1992, 46, 317-327. [PubMed]

44. Mudryj, A.N.; de Groh, M.; Aukema, H.M.; Yu, N. Folate intakes from diet and supplements may place certain Canadians at risk for folic acid toxicity. Br. J. Nutr. 2016, 116, 1236-1245. [CrossRef] [PubMed]

45. Barua, S.; Kuizon, S.; Junaid, M.A. Folic acid supplementation in pregnancy and implications in health and disease. J. Biomed. Sci. 2014, 21, 77. [CrossRef] [PubMed]

46. De Boer, A.; Bast, A.; Godschalk, R. Dietary supplement intake during pregnancy; better safe than sorry? Regul. Toxicol. Pharmacol. 2018, 95, 442-447. [CrossRef] [PubMed]

47. Hanley, D.A.; Cranney, A.; Jones, G.; Whiting, S.J.; Leslie, W.D.; Cole, D.E.; Atkinson, S.A.; Josse, R.G.; Feldman, S.; Kline, G.A.; Rosen, C. Vitamin D in adult health and disease: A review and guideline statement from Osteoporosis Canada. CMAJ 2010, 182, E610-E618. [CrossRef] [PubMed]

48. Holick, M.F.; Binkley, N.C.; Bischoff-Ferrari, H.A.; Gordon, C.M.; Hanley, D.A.; Heaney, R.P.; Murad, M.H.; Weaver, C.M. Evaluation, treatment, and prevention of vitamin D deficiency: An Endocrine Society clinical practice guideline. J. Clin. Endocrinol. Metab. 2011, 96, 1911-1930. [CrossRef] [PubMed]

49. Hollis, B.W.; Johnson, D.; Hulsey, T.C.; Ebeling, M.; Wagner, C.L. Vitamin D supplementation during pregnancy: Double-blind, randomized clinical trial of safety and effectiveness. J. Bone Miner. Res. 2011, 26, 2341-2357. [CrossRef] [PubMed]

50. Harvey, N.C.; Holroyd, C.; Ntani, G.; Javaid, K.; Cooper, P.; Moon, R.; Cole, Z.; Tinati, T.; Godfrey, K.; Dennison, E.; Bishop, N.J. Vitamin D supplementation in pregnancy: A systematic review. Health Technol. Assess. 2014, 18, 1-190. [CrossRef] [PubMed]

51. Savard, C.; Gagnon, C.; Morisset, A.S. Disparities in the timing and measurement methods to assess vitamin D status during pregnancy: A Narrative Review. Int. J. Vitam. Nutr. Res. 2018, in press.

(C) 2018 by the authors. Licensee MDPI, Basel, Switzerland. This article is an open access article distributed under the terms and conditions of the Creative Commons Attribution (CC BY) license (http:/ / creativecommons.org/licenses/by/4.0/). 